\title{
Correction to: ASO Author Reflections: Fluorescent-Guided Surgery to Augment Pancreatic Cancer Surgery
}

Willemieke S. Tummers, $\mathrm{MD}^{1,2}$, Eben L. Rosenthal, $\mathrm{MD}^{3,4}$, Alexander L. Vahrmeijer, MD, $\mathrm{PhD}^{2}$, and George A. Poultsides, $\mathrm{MD}^{5}$

${ }^{1}$ Department of Radiology, Molecular Imaging Program at Stanford (MIPS), Stanford University, Stanford, CA;

${ }^{2}$ Department of Surgery, Leiden University Medical Center, Leiden, The Netherlands; ${ }^{3}$ Department of Otolaryngology, Stanford University, Stanford, CA; ${ }^{4}$ Stanford Cancer Center, Stanford University, Stanford, CA; ${ }^{5}$ Department of Surgery, Stanford University, Stanford, CA

\section{CORRECTION TO: ANN SURG ONCOL}

HTTPS://DOI.ORG/10.1245/S10434-018-6904-9

In the original version of this article, George A. Poultsides's middle initial was incorrect. It is correct as reflected here. The original article has been revised.

The original article can be found online at https://doi.org/10.1245/ s10434-018-6904-9.

(C) Society of Surgical Oncology 2018;

Published Online: 13 November 2018

E. L. Rosenthal, MD

e-mail: elr@stanford.edu 